\title{
A Short Pseudoautosomal Region in Laboratory Mice
}

\author{
Jo Perry, Steve Palmer, Anastasia Gabriel, and Alan Ashworth ${ }^{1}$ \\ The Breakthrough Toby Robins Breast Cancer Research Centre, Institute of Cancer Research, London SW3 6JB, UK
}

\begin{abstract}
The pseudoautosomal region (PAR) of mammalian sex chromosomes is a small region of sequence identity that is the site of an obligatory pairing and recombination event between the $X$ and $Y$ chromosomes during male meiosis. During female meiosis, $\mathrm{X}$ chromosomes can pair and recombine along their entire length; recombination in the PAR is therefore $\sim 10 \times$ greater in male meiosis compared with female meiosis. A consequence of the presence of the PAR in two copies in males and females is that genes in the region escape the process of $\mathrm{X}$-inactivation. Although the structure and gene content of the human PAR at $\mathrm{Xq} / \mathrm{Yq}$ is well understood, the mouse PAR, which appears to be of independent evolutionary origin, is poorly characterized. Here we describe a yeast artificial chromosome (YAC) contig covering the distal part of the mouse $X$ chromosome, which we have used to define the pseudoautosomal boundary, that is, the point of divergence of $X$-specific and $X$-Y-identical sequences. In addition, we have investigated the size of the mouse PAR by integrating a unique restriction endonuclease recognition site just proximal to the pseudoautosomal boundary by homologous recombination. Restriction digestion of this modified DNA and pulsed field gel electrophoresis reveal that the PAR in these cells is $\sim 700 \mathrm{~kb}$. Thus, the mouse PAR, although small in size, has retained essential sex chromosome pairing functions despite its rapid rate of evolution.
\end{abstract}

The mammalian sex chromosomes are thought to have evolved from a pair of homologous chromosomes. Since the acquisition of a sex-determining function, the similarity of the $\mathrm{Y}$ chromosome with the $\mathrm{X}$ has been almost completely eroded by a series of rearrangements and deletions (Ohno 1969; Graves 1995). Additions of autosomal segments have occurred during the evolution of the mammalian $\mathrm{X}$ and $\mathrm{Y}$ chromosomes, which have resulted in an enlarged region of homology between the two chromosomes (Graves 1995). These additions have been followed by further erosion of the $\mathrm{Y}$ chromosome. Only a small region of identity between the $\mathrm{X}$ and $Y$ chromosomes of eutherian mammals has been retained and is required for sex chromosome pairing and chromosome segregation during male meiosis (Burgoyne 1982; Ellis and Goodfellow 1989; Rappold 1993). Genetic analysis has shown that loci within this region are capable of exchange between the $\mathrm{X}$ and $\mathrm{Y}$, unlike the nonhomologous portions of these chromosomes, and they therefore behave like small autosomes. However, these loci show varying degrees of sex linkage and are thus pseudoautosomal (Burgoyne 1982; Ellis and Goodfellow 1989; Rappold 1993).

In mammals, gene dosage between $\mathrm{XX}$ females and $\mathrm{XY}$ males is compensated by the transcriptional silencing of a single $\mathrm{X}$ chromosome in every female cell, a process known as $\mathrm{X}$-inactivation. Because both males and females have two copies of all pseudoautosomal genes, there is no requirement for dosage compensation, and all of the human pseudoautosomal region (PAR) genes and the single mouse PAR gene that have been examined so far have been proven to escape Xinactivation (Goodfellow et al. 1984; Ellison et al. 1992; Slim et al. 1993; Salido et al. 1996).

Two human PARs have been identified at the tips of Xp/

'Corresponding author.

E-MAIL alana@icr.ac.uk; FAX (0) 20-7878-3858.

Article and publication are at http://www.genome.org/cgi/doi/10.1101/ gr.203001.
Yp and Xq/Yq. Both PARs have been extensively characterized and are spanned by genomic contigs. The larger of the two PARs (PAR1), at the tip of $\mathrm{Xp}$ and $\mathrm{Yp}$, is $2.6 \mathrm{Mb}$ in size and contains at least 11 genes and one pseudogene (Graves et al. 1998; Ried et al. 1998). The smaller PAR (PAR2), situated at the tips of $\mathrm{Xq} / \mathrm{Yq}$, is $0.4 \mathrm{Mb}$ and contains a minimum of four genes (Freije et al. 1992; Ciccodicola et al. 2000). Although some of the genes located in the two human PARs have been cloned and mapped in the mouse, none of these genes are found in the mouse PAR (Disteche et al. 1992; Miyajima et al. 1995; D'Esposito et al. 1997; Ellison et al. 1997; Rao et al. 1997; Vermeesch et al. 1997). In fact, genes within human PAR1, when mapped in the mouse, are found on separate autosomes (Disteche et al. 1992; Miyajima et al. 1995; Ellison et al. 1997; Rao et al. 1997). Furthermore, the human ortholog of the only mouse PAR gene cloned, Steroid sulphatase, is located just proximal to the boundary within the X-unique portion (Yen et al. 1987). These observations are consistent with the idea that during the evolution of the sex chromosomes, several additions of autosomal material have occurred to the PAR, followed by continual attrition or loss of pseudoautosomal material from the Y chromosome (Graves 1995).

The pseudoautosomal boundary (PAB) is the point at which the PAR, where the $\mathrm{X}$ and $\mathrm{Y}$ chromosomes are identical, diverges into $\mathrm{X}$-specific and $\mathrm{Y}$-specific sequences and is therefore the proximal limit to legitimate $X$ and $Y$ recombination (Ellis and Goodfellow 1989). The PAB of the human short arm consists of 220 bp of incomplete sequence identity, after which the two chromosomes diverge into $\mathrm{X}$-unique and Y-unique sequences. An Alu repeat element has been inserted into the Y chromosome between the PAR and the 220-bp region of reduced homology (Ellis et al. 1989). The structure of the PAR2 boundary is quite different from that of the PAB on the short arms of the $\mathrm{X}$ and $\mathrm{Y}$. Here a LINE repeat is found on both the $\mathrm{X}$ and $\mathrm{Y}$ chromosomes, immediately adjacent to the breakpoint in homology between the long-arm PARs. It is 
thought that this long-arm PAR arose as the result of an illegitimate recombination event between LINE sequences originally present in $\mathrm{X}$ - and $\mathrm{Y}$-unique regions of the $\mathrm{X}$ and $\mathrm{Y}$ chromosomes (Kvaloy et al. 1994).

Here we have identified sequences flanking the $\mathrm{PAB}$ on the $\mathrm{X}$ chromosome in laboratory mice. Furthermore, we have developed a physical map of the mouse PAR and provide the first estimate of the physical size of this region. These data provide insights into the evolution of this unusual region of mammalian genomes.

\section{RESULTS}

\section{Sequence of the $\mathrm{PAB}$ on the $\mathrm{X}$ Chromosome}

We used chromosome walking in a yeast artificial chromosome (YAC) library to assemble a contig covering the distal part of the X-unique portion of the X chromosome. The contig we developed, part of which was reported previously (Palmer et al. 1997), contains 18 YACs and covers $\sim 2.5 \mathrm{Mb}$ (Fig. 1A). The YAC clones 42C9 and I_U18 both span the PAB. Several additional X-linked markers, DXMit71, DXMit100 (Dietrich et al. 1996), and M-05615 (all characterized by the Whitehead Institute/Massachusetts Institute of Technology [MIT] Genome Center), as well as the two genes Amelogenin (Amel; Snead et al. 1985) and Holocytochrome c-type synthetase (Hccs; Schaefer et al. 1996) have been placed on this map by polymerase chain reaction (PCR) amplification (Fig 1A).

Two sequence tagged site (STS) markers, DXYCbl2 and DXCbl1, derived from the YAC contig (Palmer et al. 1997), are located on either side of the mouse PAB (Fig. 1B). Oligonucleotides derived from these markers were used to amplify a fragment spanning the $\mathrm{PAB}$ on the $\mathrm{X}$ chromosome from C57BL/6 (B6) female genomic DNA by long-template PCR.
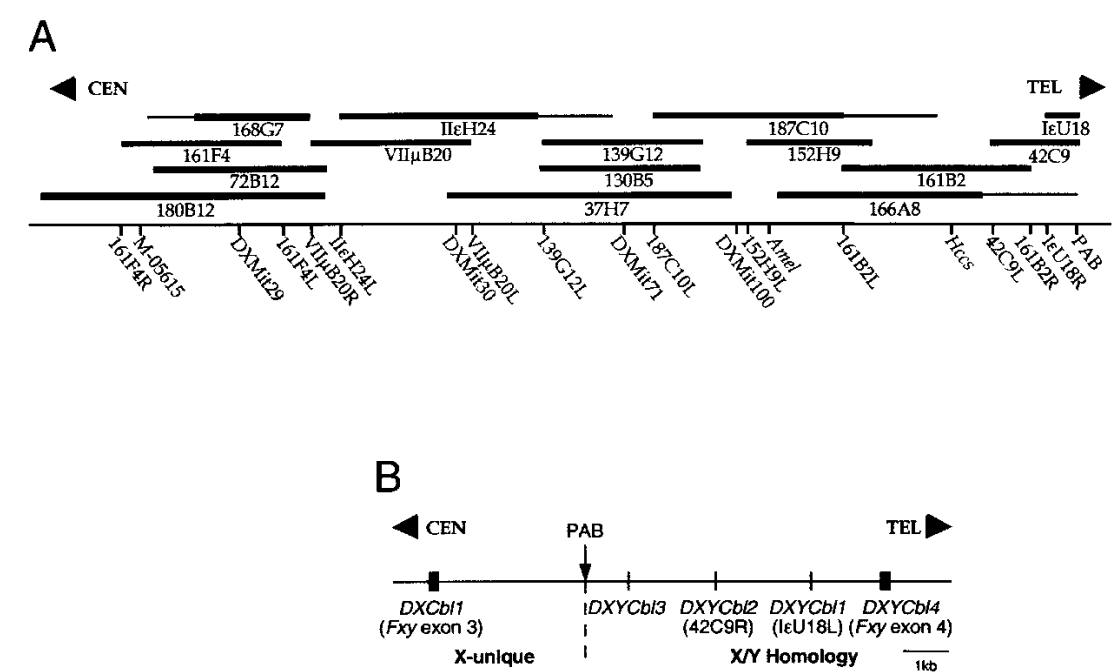

Figure 1 Isolation of the mouse pseudoautosomal boundary (PAB). (A) A genomic contig covering the distal part of the mouse $X$ chromosome consisting of overlapping YAC and bacterial artificial chromosomes (BAC) clones covering the region proximal of, and including, the PAB. Boxed regions of YACs indicate the presence of $X$ chromosomal DNA, whereas lines indicate the presence of non- $X$ chromosomal DNA. The STSs derived from these YACs and their relative distances are indicated below the line. The suffix L or R on the STS name indicates the left or right arm of the YAC from which the STS is derived. The position of additional genetic markers localized to the contig are also indicated. TEL and CEN indicate telomeric and centromeric directions, respectively. The figure is not to scale; however, the total walk covers $\sim 2.5 \mathrm{Mb}$. (B) Schematic representation of a 10-kb genomic fragment spanning the mouse $P A B$, showing markers isolated from this region. Black boxes indicate markers derived from Fxy exon sequence.
The resulting 8.9-kb band was cloned into a plasmid for further analysis. Figure $1 \mathrm{~B}$ shows a schematic of the $8.9-\mathrm{kb}$ clone spanning the PAB and some of the markers used for physical mapping. Using a combination of PCR assays and Southern blotting with markers and probes derived from this clone, the exact position of the boundary between $\mathrm{X}$-unique and $\mathrm{XY}$ gion. An adjacent XY homologous probe, DXYCbl4, was then a sequences that were identical up to the predicted boundPrimers were designed to this novel sequence, and it was shown that by using a primer within DXYCbl4, it was possible to amplify a fragment by PCR across the boundary to an Xunique primer (data not shown). It was assumed at the time specific. However, the sequence proved to map to both $\mathrm{X}$ and $Y$, and it soon became clear that fragments derived from the novel divergent sequence hybridized exclusively to a repetitive band present in the PAR. This repeat unit has been preand appears to vary in copy number between different strains et al. 1996a,b)

Corresponding Sequences in Mus spretus are X-Specific To determine whether the PAB is similarly located in other male and female genomic DNA from different mouse strains. This analysis showed that although the number of pseudoautosomal repeats may vary from strain to strain, the position of the boundary was still located between the STS markers DXCbl1 and DXYCbl1 in all strains tested (B6, C57BL/10, 129 Sv/J, FVB; Palmer et al. 1997; data not shown).

To determine whether the $\mathrm{PAB}$ is similarly located in other species of mice, the location of markers flanking the $\mathrm{PAB}$ in laboratory mice was investigated in SPE. Oligonucleotides derived from $\mathrm{PAB}$ flanking markers were used to amplify fragments by PCR from $(\mathrm{B} 6 \times \mathrm{SPE}) \mathrm{F}_{1}$ genomic DNA derived from a male mouse containing a B6-derived $\mathrm{X}$ chromosome and a SPE-derived Y chromosome. One such marker, DXYCbl1, which is pseudoautosomal in laboratory mice, contains a sequence variant involving an A (B6) to G (SPE) nucleotide difference at position 75 (Fig. 3). Analysis of $(\mathrm{B} 6 \times \mathrm{SPE}) \mathrm{F}_{1}\left(\mathrm{X}^{\mathrm{B} 6} \mathrm{Y}^{\mathrm{SPE}}\right)$ genomic DNA showed that only the laboratory (B6) variant was present in this sample, indicating that $D X Y$ Cbl1 is not pseudoautosomal in SPE mice. The same assay was performed on an admixture of equal amounts of B6 and SPE genomic DNA; both alleles were represented in the amplification product, showing the absence of template competition. 


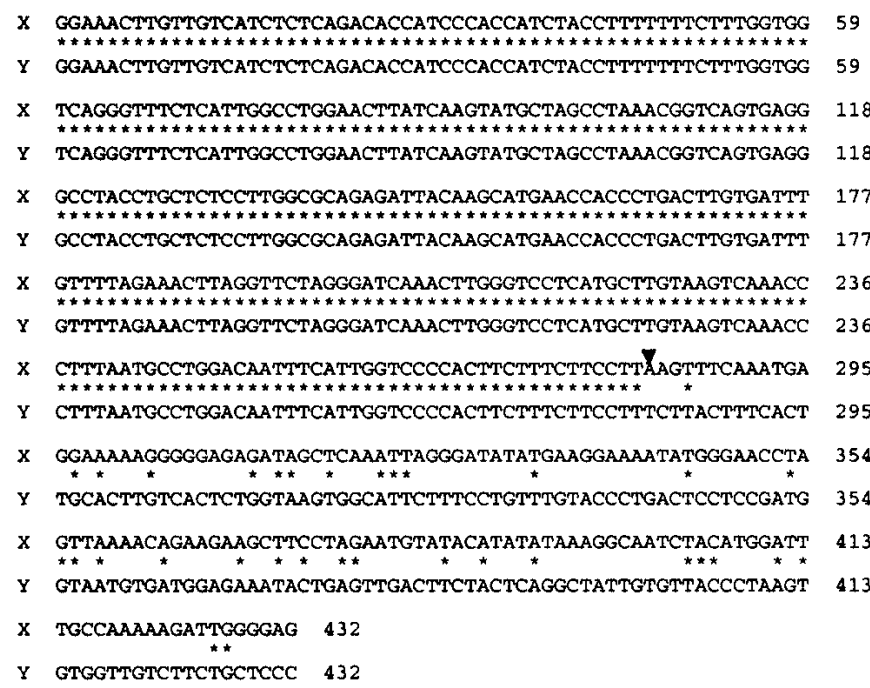

Figure 2 Structure of the mouse pseudoautosomal boundary (PAB). Sequence of $400 \mathrm{bp}$ spanning the mouse $\mathrm{PAB}$ on the $X$ chromosome, showing the point the $X-Y$ identical pseudoautosomal region (PAR) diverges into $X$ unique sequence (black triangle). Identical nucleotides are indicated by asterisks.

Haplotype analysis of a second pseudoautosomal marker in laboratory mice, $D X Y C b l 3$, showed that the markers flanking the $\mathrm{PAB}$ of laboratory mice are in fact $\mathrm{X}$ unique in SPE mice. B6 DNA amplified with oligonucleotides derived from $D X Y C b l 3$ has a DdeI site that is not present in SPE, which allows a haplotype analysis of EUCIB backcross animals for this locus (European Backcross Collaborative Group 1994). Using animals from the backcross to B6, it was possible to show that the allele mapped to the very distal portion of the SPE X chromosome (data not shown).

\section{Inserting a Unique Restriction Endonuclease Site Proximal to the PAB}

Our strategy for sizing the mouse PAR was to use direct cleavage by a restriction enzyme site located close to the PAB, followed by gel electrophoresis and detection of the restriction fragment by Southern blot hybridization. We could not use sites present naturally, as these would also cleave the PAR frequently. Hence, we engineered a rare-cutting restriction enzyme (I-SceI) site just proximal to the mouse PAB by homologous recombination in 129 embryonic stem (ES) cells. I-SceI is a so-called meganuclease encoded by the yeast mitochondrial genome that recognizes an 18-bp site. This site appears not to be present in the mammalian genome; thus, one would expect I-SceI to cleave only at the introduced DNA. A replacement targeting vector (Fig. 4A) was designed to completely remove exon 2 of the mouse $F x y$ gene and replace it with a $L a c Z$ reporter gene. A neomycin resistance (neo) gene, under the control of Phosphoglycerate kinase, promoter was used for selection. In addition, the vector contains a unique I-SceI restriction site (Fig. 4A; Jacquier and Dujon 1985; Monteilhet et al. 1990). The insertion of this I-SceI site just proximal to the PAB provides an opportunity to study the physical size of the mouse PAR.

129 ES cells were transfected with the linearized Fxy targeting vector, $\mathrm{pFXYKO}$, and then subjected to selection with media containing G418. Individual resistant colonies were isolated and tested for correct integration of the targeting vec- tor by PCR and Southern hybridization. Of a total of 312 colonies screened by PCR, two clones were shown to have the correctly targeted allele (Fig 4B).

\section{Direct Sizing of the Mouse PAR}

To size the mouse PAR, high-molecular-weight genomic DNA embedded in agarose plugs was prepared from wildtype ES cells and ES cells targeted with the Fxy targeting vector. The plugs were digested with I-SceI meganuclease, and the DNA was separated by pulsed field gel electrophoresis, acid nicked, and transferred onto Hybond $\mathrm{N}^{+}$membrane. The blot was then hybridized with two pseudoautosomal fragments: a 3' fragment of the Fxy gene (Palmer et al. 1997) or a fragment of the Mov15 repeats present in the PAR (Harbers et al. 1990). Both of these probes are located within the pseudoautosomal repeat units and will therefore give a strong hybridization signal because of the presence of multiple copies. Both probes hybridized to a single band of $\sim 750 \mathrm{~kb}$ in the targeted ES cells but not in the wild-type ES cells (Fig. 5). The integrated I-SceI restriction site is located at exon 2 of the Fxy gene. This exon is $\sim 30$ to $50 \mathrm{~kb}$ proximal to the mouse $\mathrm{PAB}$, as estimated by pulsed field gel electrophoresis and Southern analysis (data not shown). Taken together, these results estimate the size of the PAR in 129 mice to be $\sim 700$ to $720 \mathrm{~kb}$.

\section{Physical Mapping of the Mouse PAR}

To investigate the physical organization of the PAR, several bacterial artificial chromosomes (BACs) were isolated and checked for the presence of known X-linked and PAR markers by PCR. This was achieved by screening GenBank (Genome Survey Sequences) with sequences derived from the 8.9-kp region spanning the $\mathrm{PAB}$ (see above). One of the BACs identified (clone RPCI-23-306N24; http://www.chori.org/ bacpac/ 23framefmouse.htm) was shown to contain exons 4 to 10 of the Fxy gene by PCR amplification using exon-specific oligonucleotides. Even though the size of RPCI-23-306N24 is only $\sim 75 \mathrm{~kb}$, both end sequences derived from this BAC align with the pseudoautosomal portion of the $8.9-\mathrm{kb}$ fragment spanning the $\mathrm{PAB}$. This indicates that the $\mathrm{BAC}$ is derived from the repetitive region within the PAR. Investigation of the STS content of this BAC with Southern blotting and PCR analysis indicated that it contains at least one repeat unit (data not

B6
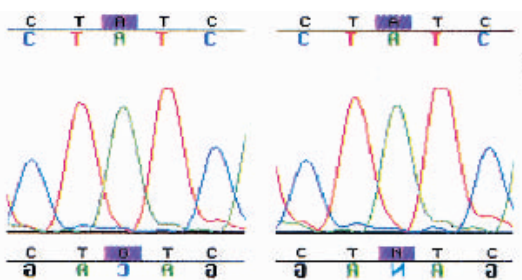

(B6xSPE) $\mathrm{F}_{1}$ male

SPE
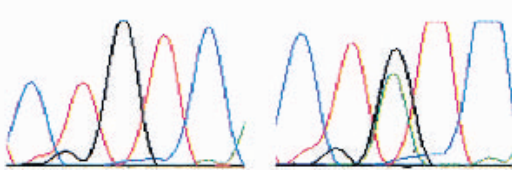

$\mathrm{B} 6+\mathrm{SPE}$

Figure 3 A Mus musculus pseudoautosomal marker is $X$ unique in Mus spretus. The pseudoautosomal marker, DXYCb/1, was amplified by polymerase chain reaction (PCR) from genomic DNA derived from $\mathrm{B} 6$ (B6), SPE (SPE), (B6 $\times$ SPE) $F_{1}$ male mice, and an admixture of $\mathrm{B} 6$ + SPE DNA. PCR fragments were sequenced directly, and chromatograms are displayed. 


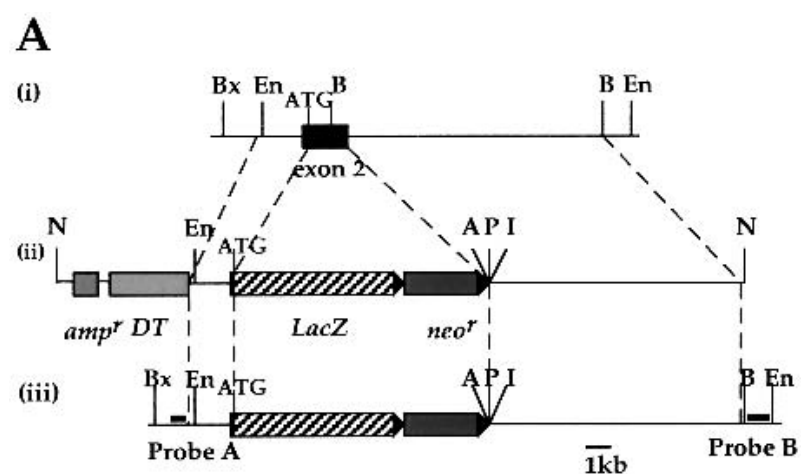

B

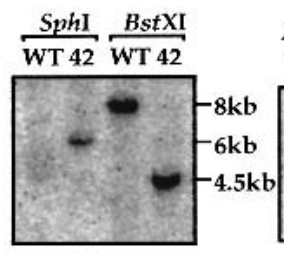

(i)

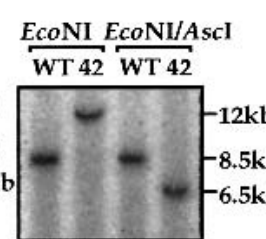

(ii)

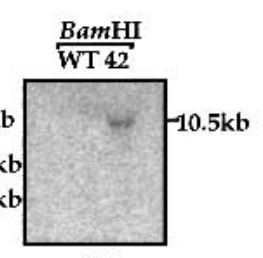

(iii)
Figure 4 Introduction of an I-Scel restriction site proximal to the pseudoautosomal boundary (PAB). (A) Targeting strategy for the insertion of an I-Scel restriction site proximal to the PAB: wild-type Fxy allele (i), Fxy targeting vector (ii), and targeted Fxy allele (iii). The region of the gene surrounding exon two (black box) of the Fxy gene (top panel) was replaced by a LacZ reporter gene (diagonal lines), which is in frame with the initiation codon (ATG), and a neo selection cassette (dark gray box) flanked by two LoxP sites (black triangles). An negative selection gene, Diphtheria toxin (dotted box), and an ampicillin resistance gene (light grey box), are located upstream of the 5' homology region. The bottom panel shows the correctly targeted allele and the position of two probes used for Southern hybridization (probes $\mathrm{A}$ and $\mathrm{B}$ ). Restriction enzyme sites indicated are $\mathrm{A}, \mathrm{Ascl} ; \mathrm{B}$, BamHI; Bx, BstXI; En, EcoNI; I, I-Scel; N, Notl; and P, Pacl. (B) Analysis of targeted clones by Southern hybridization. Genomic DNA from wild-type (WT) and targeted embryonic stem cells (Perry and Ashworth 1999) digested with restriction enzymes and hybridized to probe A (i), probe B (ii), or a probe derived from the neo gene (iii). Sizes estimated from molecular weight markers are indicated on the right.

shown). The genomic structure of $F x y$ was investigated by using oligonucleotides derived from each exon of the gene to amplify interspersed introns by PCR on B6 and RPCI-23306 N24 genomic DNA. This analysis showed that the mouse Fxy gene has a similar structure to the human gene (Fig. 6). However, in general, the intron sizes of the mouse gene are smaller than those seen for the human gene (Quaderi et al. 1997; Perry et al. 1998).

Several markers, including DXYMov15 (Harbers et al. 1990), PAR-4 (Kipling et al. 1996b), and an interstitial telo-

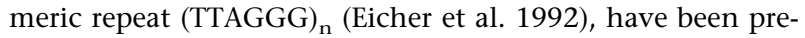
viously localized to the mouse PAR. In an attempt to clarify the physical organization of this region, these markers were hybridized to genomic DNA derived from the BAC clone RPCI-23-306N24 cut with restriction enzymes. All three markers hybridize to genomic DNA derived from RPCI-23306N24 (data not shown). It therefore appears that the repeat unit contains DXYMov15, PAR-4, (TTAGGG) $)_{\mathrm{n}}$, as well as the seven 5' exons of the Fxy gene (Fig. 6). However, the possibility that these markers are also present in the remaining portion of the PAR cannot be ruled out.

\section{DISCUSSION}

The location and function of the PAR of mammalian genomes have resulted in the acquisition of unique genetic, physical, and evolutionary properties (Burgoyne 1982; Ellis and Goodfellow 1989; Rappold 1993; Graves 1995). Because of these properties, the only well-characterized PAR, that of humans, may not be typical of the PARs of other mammals. Here we describe the size and structural organization of the mouse PAR, which is evolutionarily independently derived from that of humans and has thus far not been characterized in detail.

By definition, the PAR is identical on both the $\mathrm{X}$ and $\mathrm{Y}$ chromosomes, but at the $\mathrm{PAB}$, the $\mathrm{X}$ and $\mathrm{Y}$ chromosomes should diverge. After an extensive genomic walk (Fig. 1), we have identified the point of sequence divergence between the homologous X/Y PAR and X-unique sequences in the mouse (Fig. 2). However, the boundary is more complex than a simple transition from pseudoautosomal sequence into $\mathrm{X}$ unique or Y-unique sequences. A variable tandem repeat array is located adjacent to this PAB on the PAR side. The number of repeat units appears to vary widely both between different strains of mice as well as between individuals from the same strain, according to estimates of copy number from Southern hybridization (Kipling et al. 1996a,b; Palmer et al. 1997; S. Palmer and A. Ashworth, unpubl.). At the PAB, the X chromosome diverges from the $\mathrm{Y}$ chromosome into $\mathrm{X}$-unique sequence. However, at the point of divergence, what is expected

A

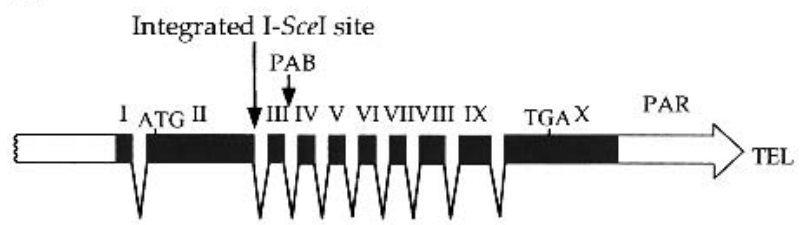

B

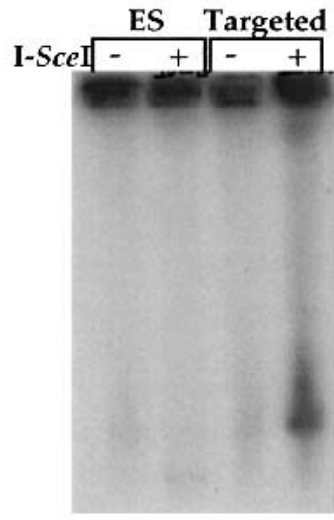

Mov15

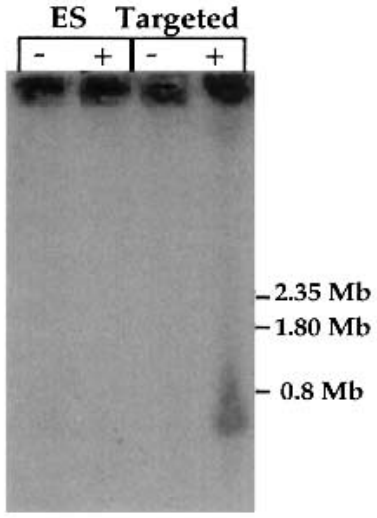

Fxy 3'
Figure 5 Direct sizing of the pseudoautosomal region (PAR). (A) Schematic representation of the genomic structure of the Fxy gene, indicating the position of the pseudoautosomal boundary (PAB) and the integrated I-Scel site. Exons are indicated by roman numerals, and the initiation and termination codons (ATG and TGA, respectively) are shown. (B) Southern analysis of the size of the PAR in 129 mice. Wild-type embryonic stem cell (ES) and targeted embryonic stem cell (Targeted) genomic DNA was incubated with $(+)$ or without $(-)$ the restriction enzyme I-Scel and were hybridized to the pseudoautosomal probes Mov15 or Fxy3. Size, estimated from molecular weight markers (Hansenula wingei chromosomes), is indicated on the right. 


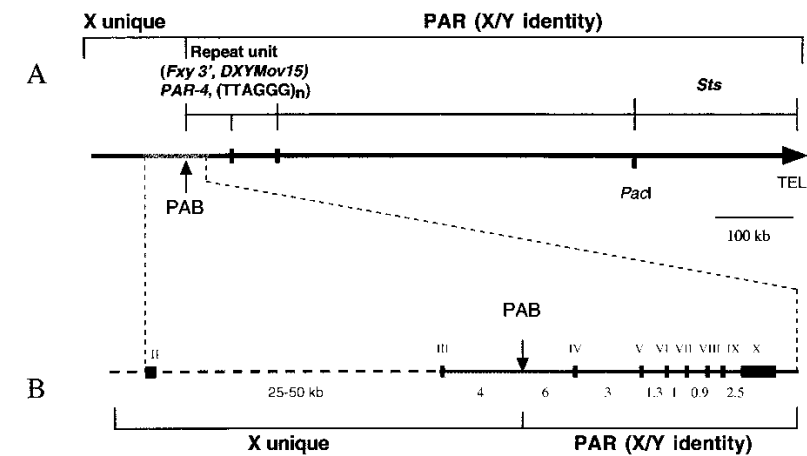

Figure 6 The mouse pseudoautosomal region (PAR). (A) A physical map of the PAR of laboratory mice (129Sv) incorporating a previously reported study (Kipling et al. 1996a) as well as results presented here. The location of the Fxy gene is indicated by a gray line. PAB indicates the position of the pseudoautosomal boundary; TEL, of the telomere. The presence of two repeat units containing the $3^{\prime}$ of Fxy, DXYMov15, $P A R-4$, and the interstitial telomeric repeat (TTAGGG) ${ }_{n}$ are also indicated. The positions of a Pacl site and the Steroid sulphatase (Sts) gene have been taken from a study by Kipling et al. (1996a). (B) Schematic of the genomic organization of the Fxy gene in laboratory mice. Exons are indicated by gray boxes. The first three exons are $\mathrm{X}$ unique, whereas the remaining exons are pseudoautosomal. Intron sizes, where known, are indicated (kb). PAB indicates the position of the pseudoautosomal boundary.

to be a Y-specific sequence on the $\mathrm{Y}$ chromosome is in fact part of the repeat sequence present in the PAR array. These observations can be explained by proposing that the $\mathrm{X}$ - and $Y$-specific domains diverge from the repeat unit at different points within the sequence. So the $\mathrm{PAB}$ of laboratory mice appears to be the point of divergence of the $\mathrm{X}$ chromosome with the repeat unit on the Y chromosome. The variation in the copy number of the repeat suggests that this domain undergoes frequent alteration in size, which may be caused by recombination slippage and unequal exchange. Recombination slippage and unequal exchange would give rise to a range of allele sizes, and indeed, this region is known to undergo frequent alterations in structure (Kipling et al. 1996a,b). For example, PacI fragments hybridizing to the pseudoautosomal probes pMov15/1 and PAR-4 in B6 animals show variations between 0.6 and $2 \mathrm{Mb}$ (Kipling et al. 1996a).

The sequence at the $\mathrm{PAB}$, that is, the point of divergence between $\mathrm{X}$ and $\mathrm{Y}$ PARs, has no obvious distinguishing features. A search of the European Molecular Biology Laboratory and GenBank databases revealed no strong homology with any previously isolated sequence in any species. The sequences of the $\mathrm{X}$-unique region and the repeat region, adjacent to the $\mathrm{PAB}$, were compared using computer alignment, but no similarities were found. This lack of apparent residual sequence homology proximal with the boundary is unlike the situation for the human PAR1, in which there is evidence for a more proximal ancestral boundary (Ellis et al. 1989).

Although some progress has been made previously in identifying and mapping pseudoautosomal markers (Kipling et al. 1996a), this region of the mouse genome has remained largely uncharacterized. During the course of this investigation, we identified a mouse BAC clone derived from the repetitive region of the mouse PAR. We investigated the composition of the repeat unit by Southern hybridization and PCR analysis of this BAC with known pseudoautosomal markers. This analysis indicated that the PAR repeat unit contains the markers PAR-4, DXYMov15, the 3' seven exons of the Fxy gene, as well as an interstitial telomere repeat (TTAGGG) . Although the presence of additional copies of these markers outside the repeat unit cannot be ruled out, it appears that these markers are all present within the proximal repetitive part of the PAR (Fig. 6).

The major human PAR is $2.6 \mathrm{Mb}$ in length. We wished to determine the size of the PAR in mice, as previously only rough estimates of the size of the mouse PAR, based on genetic and cytogenetic measurements, were available (Eicher et al. 1992). We targeted a restriction enzyme (I-SceI) recognition site not normally present in the mouse genome to a position just proximal of the mouse PAB in 129 ES cells. This provided an opportunity to estimate the size of the PAR by cutting off the end of the chromosome. We used pulsed field gel electrophoresis and Southern blot hybridization to estimate the size of the PAR in these cells as being $\sim 700$ to $720 \mathrm{~kb}$. The uncertainty in this figure is based on our estimate of the distance between exon 2 of the Fxy gene (position of I-SceI integration) and the $\mathrm{PAB}$ as being 30 to $50 \mathrm{~kb}$. Our estimate is much smaller than the previous tentative estimates of 3 to $4 \mathrm{Mb}$ (Eicher et al. 1992). This difference is most likely to be owing to the genetic methods used previously, which may have been confounded by the frequent cross-over and, indeed, double cross-over events that occur in this region (Harbers et al. 1986; Keitges et al. 1987; Soriano et al. 1987). Furthermore, our estimate of 700 to $720 \mathrm{~kb}$ is also much less than the PAR1 of humans, which is $2.6 \mathrm{Mb}$.

We noted above that the PAR proximal region contains a repeat unit of which an estimated two copies are present in the ES cell line that we analyzed. However, the repeat unit has been shown to vary in copy number (Kipling et al. 1996a,b; Palmer et al. 1997) between strains and may be completely absent in some, as in the inbred strain FVB, or present in multiple copies, numbering as many as 24 , as seen in a C57BL/10 individual (Palmer et al. 1997). Although the size of the repeat unit is not known, it is estimated to be at least 16 $\mathrm{kb}$ and may therefore cause some variation in the overall size of the PARs of inbred strains. Therefore, the size of the PAR we described here is unlikely to be accurate for all mouse strains, as the number of repeats present varies.

In addition to being substantially smaller than the human PAR1, the mouse PAR appears to share little sequence similarity. This is a reflection of the distinct evolutionary origin of these two regions, as the human PAR1 has evolved by the addition of separate autosomal segments that have not occurred in the mouse lineage (Graves 1995). Furthermore, sequences within the PARs of both mice and humans appear to be subject to an accelerated evolution. Genes within the PAR appear to evolve more rapidly than their nonpseudoautosomal counterparts in humans or mice. Two human PAR genes, GM-CSFR $\propto$ and $I l 3 R \propto$, have been shown to be considerably diverged from their autosomal mouse orthologs (Ellison et al. 1996). In addition, the mouse PAR gene, Steroid sulphatase, shares little sequence similarity with the human Steroid sulphatase gene located within Xp22.3 (Yen et al. 1987; Salido et al. 1996). A clear illustration of this accelerated divergence can be seen in the $F x y$ gene from laboratory mice, which spans the PAB in this species of mouse. We recently showed that the $3^{\prime}$ portion of this gene was estimated to evolving $\sim 170$-fold faster than the corresponding region in SPE mice, which is X unique (Perry and Ashworth 1999). We attributed this finding to the high rate of recombination. Therefore, one would expect a very different sequence composition for the mouse (and human PARs). However, large- 
scale rearrangements have also taken place (Graves 1995). This is revealed by the analysis of laboratory mice (Mus musculus) PAR sequences in Mus spretus (Fig. 3).

The PAR markers derived from within the repeat unit are clearly not pseudoautosomal in SPE but rather are X unique. The distal X chromosomal location of these markers in SPE suggests that the PAB in this species of mice must be distal to that of laboratory (Mus musculus) strains. It is already known that the distal $\mathrm{X}$ differs in these two species with respect to the presence of two genes, Clcn4 and Fxy. Clcn4, a chloride channel gene, is present on the distal X chromosome in SPE, whereas the gene is present on chromosome 7 in all of the Mus musculus subspecies (Palmer et al. 1995; Rugarli et al. 1995). The Fxy gene is also differentially located in laboratory and SPE mice, being wholly $\mathrm{X}$ unique in the latter and spanning the PAB in the former (Perry and Ashworth 1999). These findings may be related. A possible hypothesis explaining these observations is that Clcn4 is very close to the ancestral and SPE boundary, and a single, probably complex rearrangement, event not only transferred the gene onto an autosome in laboratory mice but also destabilized the boundary and its surrounding region. This translocation event may also have resulted in Fxy being brought into a position spanning the boundary in these mice.

Taken together, these data indicate that the distal $\mathrm{X}$ chromosome of laboratory mice has undergone substantial rearrangements since its divergence from SPE mice $\sim 3 \mathrm{Myr}$ ago (Ferris et al. 1983). Hence, the PAR of these mice may represent a rearranged or deleted version of the PAR compared with that of other species of mice. The $F_{1}$ males produced by intercrossing these two species are infertile, very probably as a consequence of heterozygosity in the XY pairing region leading to the nonpairing of the $\mathrm{X}$ and $\mathrm{Y}$, which is a prerequisite for spermatogenic survival through the meiotic process (Burgoyne et al. 1992). Clearly, the altered position of the boundary must be a contributory factor in the lack of sufficient pairing capacity. The determination of the position of the $\mathrm{PAB}$ in other mouse species such as Mus musculus musculus and Mus castaneus may clarify the extent to which the Mus musculus domesticus PAR is representative of that of other mouse species. Furthermore, the introduction of a means to separate the PAR from the nonrecombining portions of the sex chromosomes opens up the possibility of detailed sequence analysis of the region.

\section{METHODS}

\section{STS PCR Markers and YAC Libraries}

YAC clones were isolated from either the MRC HGMP combined mouse YAC library, from which the YACs I_U18, II_H24, and VII_B20 were isolated, or the MIT mouse YAC library (Research Genetics), from which all the other YACs were obtained. The BAC clone RPCI-23-306N12 was isolated using bioinformatic techniques as described in Results and is derived from the RPCI-23 Female (B6) Mouse BAC Library. The process of library screening and the isolation of DXYCbl1, $D X Y C b l 2, D X Y C b l 3$, and DXCbl1 have been described previously (Palmer et al. 1997). The marker DXYCbl4 is derived from exon four of the Fxy gene using the oligonucleotides AATGCATCCCGTCAAGAAGC and GCCTTCTTTAATCTTTGTTCC. DXYMov15 (Harbers et al. 1990), PAR-4 (Kipling et al. 1996b), and the interstitial telomeric repeat (TTAGGG) ${ }_{\mathrm{n}}$ (Eicher et al. 1992) have all been described previously. The sequences of the other markers generated during the walk are available on request.

\section{Physical Mapping}

For conventional agarose gels, genomic DNA was digested with restriction enzymes and electrophoresed on $0.8 \%$ agarose gels. The DNA was transferred to nylon membranes and hybridized overnight by the method of Church and Gilbert (1984) or for shorter periods using Rapid-Hyb (Amersham). For pulsed field gels, DNA embedded in agarose was prepared from ES cells and digested with restriction enzymes as described (Birren and Lai 1993). Samples were fractionated on a $1 \%$ agarose gel using a CHEF DRII (Bio-Rad) pulsed field gel electrophoresis apparatus according to the manufacturer's instructions. Molecular weight markers were Hansenula wingei chromosomes (Bio-Rad).

\section{ES Cell Culture}

Male 129 ES cells (Go Germline, Genome Systems) were grown under $5 \% \mathrm{CO}_{2}$ in ES cell medium, containing leukemia inhibitory factor (ESGROTM, GIBCO BRL). ES cells were grown in tissue culture dishes on a feeder layer of mitotically inactivated mouse embryonic fibroblasts derived from a 12day embryo transgenic for the neomycin resistance gene. ES cells used for isolation of genomic DNA were passaged without the feeder cells at least twice and grown in dishes treated with $0.1 \%(\mathrm{w} / \mathrm{v})$ gelatin. For ES cell transfection, $2 \times 10^{7}$ cells were electroporated with a Bio-Rad Genepulser II at $0.270 \mathrm{~V}$ (500 $\mu \mathrm{FA}$ with $20 \mu \mathrm{g}$ of linearized pFXYKO vector), transferred to $10 \mathrm{~cm}^{2}$ dishes, and allowed to recover in ES cell medium overnight. After $24 \mathrm{~h}$, cells were treated with selection media consisting of $400 \mu \mathrm{g} / \mathrm{mL}$ G418 $(200 \mu \mathrm{g} / \mathrm{mL}$ active concentration) for the next $6 \mathrm{~d}$. Surviving clones were isolated and tested for correct integration of pFXYKO by PCR and Southern blotting.

\section{ACKNOWLEDGMENTS}

This work was supported by the Wellcome Trust, The Medical Research Council, the Mary-Jean Mitchell Green Foundation, and Breakthrough Breast Cancer.

The publication costs of this article were defrayed in part by payment of page charges. This article must therefore be hereby marked "advertisement" in accordance with 18 USC section 1734 solely to indicate this fact.

\section{REFERENCES}

Birren, B. and Lai, E. 1993. Pulsed field gel electrophoresis: A practical guide. Academic Press, San Diego.

Burgoyne, P.S. 1982. Genetic homology and crossing over in the X and Y chromosomes of mammals. Hum. Genet. 61: 85-90.

Burgoyne, P.S., Mahadevaiah, S.K., Sutcliffe, M.J., and Palmer, S.J. 1992. Fertility in mice requires X-Y pairing and a Y-chromosomal "spermiogenesis" gene mapping to the long arm. Cell 71: 391-398.

Church, G.M. and Gilbert, W. 1984. Genomic sequencing. Proc. Natl. Acad. Sci. 81: 1991-1995.

Ciccodicola, A., D'Esposito, M., Esposito, T., Gianfrancesco, F., Migliaccio, C., Miano, M.G., Matarazzo, M.R., Vacca, M., Franze, A., Cuccurese, M., et al. 2000. Differentially regulated and evolved genes in the fully sequenced $\mathrm{Xq} / \mathrm{Yq}$ pseudoautosomal region. Hum. Mol. Genet. 9: 395-401.

D’Esposito, M., Matarazzo, M.R., Ciccodicola, A., Strazzullo, M., Mazzarella, R., Quaderi, N.A., Fujiwara, H., Ko, M.S., Rowe, L.B., Ricco, A., et al. 1997. Differential expression pattern of XqPAR-linked genes SYBL1 and IL9R correlates with the structure and evolution of the region. Hum. Mol. Genet. 6: 1917-1923.

Dietrich, W.F., Miller, J., Steen, R., Merchant, M.A., Damron-Boles, D., Husain, Z., Dredge, R., Daly, M. J., Ingalls, K.A., O'Connor, T.J., et al. 1996. A comprehensive genetic map of the mouse genome. Nature 380: 149-152.

Disteche, C.M., Brannan, C.I., Larsen, A., Adler, D.A., Schorderet, D.F., Gearing, D., Copeland, N.G., Jenkins, N.A., and Park, L.S. 1992. The human pseudoautosomal GM-CSF receptor $\alpha$-subunit gene is autosomal in mouse. Nat. Genet. 1: 333-336.

Eicher, E.M., Lee, B.K., Washburn, L.L., Hale, D.W., and King, T.R. 
1992. Telomere-related markers for the pseudoautosomal region of the mouse genome. Proc. Natl. Acad. Sci. 89: 2160-2164.

Ellis, N. and Goodfellow, P.N. 1989. The mammalian pseudoautosomal region. Trends Genet. 5: 406-410.

Ellis, N.A., Goodfellow, P.J., Pym, B., Smith, M., Palmer, M., Frischauf, A.M., and Goodfellow, P.N. 1989. The pseudoautosomal boundary in man is defined by an Alu repeat sequence inserted on the Y chromosome. Nature 337: 81-84.

Ellison, J.W., Ramos, C., Yen, P.H., and Shapiro, L.J. 1992. Structure and expression of the human pseudoautosomal gene XE7. Hum. Mol. Genet. 1: 691-696.

Ellison, J.W., Li, X., Francke, U., and Shapiro, L.J. 1996. Rapid evolution of human pseudoautosomal genes and their mouse homologs. Mamm. Genome 7: 25-30.

Ellison, J.W., Wardak, Z., Young, M.F., Gehron Robey, P., Laig-Webster, M., and Chiong, W. 1997. PHOG: A candidate gene for involvement in the short stature of Turner syndrome. Hum. Mol. Genet. 6: 1341-1347.

European Backcross Collaborative Group 1994. Towards high resolution maps of the mouse and human genomes: A facility for ordering markers to $0.1 \mathrm{cM}$ resolution. Hum. Mol. Genet. 3: $621-627$

Ferris, S.D., Sage, R.D., Prager, E.M., Ritte, U., and Wilson, A.C. 1983. Mitochondrial DNA evolution in mice. Genetics 105: $681-721$.

Freije, D., Helms, C., Watson, M.S., and Donis Keller, H. 1992. Identification of a second pseudoautosomal region near the $\mathrm{Xq}$ and Yq telomeres. Science 258: 1784-1787.

Goodfellow, P., Pym, B., Mohandas, T., and Shapiro, L.J. 1984. The cell surface antigen locus, MIC2X, escapes X-inactivation. Am. J. Hum. Genet. 36: 777-782.

Graves, J.A. 1995. The evolution of mammalian sex chromosomes and the origin of sex determining genes. Philos. Trans. R. Soc. Lond. B. Biol. Sci. 350: 305-311.

Graves, J.A.M., Wakefield, M.J., and Toder, R. 1998. The origin and evolution of the pseudoautosomal regions of human sex chromosomes. Hum. Mol. Genet. 7: 1991-1996.

Harbers, K., Soriano, P., Muller, U., and Jaenisch, R. 1986. High frequency of unequal recombination in pseudoautosomal region shown by proviral insertion in transgenic mouse. Nature 324: $682-685$.

Harbers, K.F., Francke, U., Soriano, P., Jaenisch, R., and Muller, U. 1990. Structure and chromosomal mapping of a highly polymorphic repetitive DNA sequence from the pseudoautosomal region of the mouse sex chromosomes. Cytogenet. Cell Genet. 53: 129-133.

Jacquier, A. and Dujon, B. 1985. An intron-encoded protein is active in a gene conversion process that spreads an intron into a mitochondrial gene. Cell 41: 383-394.

Keitges, E.A., Schorderet, D.F., and Gartler, S.M. 1987. Linkage of the Steroid sulfatase gene to the sex-reversed mutation in the mouse. Genetics 116: 465-468.

Kipling, D., Salido, E.C., Shapiro, L.J., and Cooke, H.J. 1996a. High frequency de novo alterations in the long-range genomic structure of the mouse pseudoautosomal region. Nat. Genet. 13: $78-80$.

Kipling, D., Wilson, H.E., Thomson, E.J., Lee, M., Perry, J., Palmer, S., Ashworth, A., and Cooke, H.J. 1996b. Structural variation of the pseudoautosomal region between and within inbred mouse strains. Proc. Natl. Acad. Sci. 93: 171-175.

Kvaloy, K., Galvagni, F., and Brown, W.R. 1994. The sequence organization of the long arm pseudoautosomal region of the human sex chromosomes. Hum. Mol. Genet. 3: 771-778.

Miyajima, I., Levitt, L., Hara, T., Bedell, M.A., Copeland, N.G., Jenkins, N.A., and Miyajima, A. 1995. The murine interleukin-3 receptor alpha subunit gene: Chromosomal localization, genomic structure, and promoter function. Blood 85: 1246-1253.

Monteilhet, C., Perrin, A., Thierry, A., Colleaux, L., and Dujon, B. 1990. Purification and characterization of the in vitro activity of
I-Sce I, a novel and highly specific endonuclease encoded by a group I intron. Nucleic Acids Res. 18: 1407-1413.

Ohno, S. 1969. Evolution of the sex chromosomes in mammals. Ann. Rev. Genet. 3: 495-524.

Palmer, S., Perry, J., and Ashworth, A. 1995. A contravention of Ohno's law in mice. Nat. Genet. 10: $472-476$.

Palmer, S., Perry, J., Kipling, D., and Ashworth, A. 1997. A gene spans the pseudoautosomal boundary in mice. Proc. Natl. Acad. Sci. 94: 12030-12035.

Perry, J. and Ashworth, A. 1999. Evolutionary rate of a gene affected by chromosomal position. Curr. Biol. 9: 987-989.

Perry, J., Feather, S., Smith, A., Palmer, S., and Ashworth, A. 1998. The human FXY gene is located within Xp22.3: Implications for evolution of the mammalian X chromosome. Hum. Mol. Genet. 7: 299-305

Quaderi, N.A., Schweiger, S., Gaudenz, K., Franco, B., Rugarli, E.I., Berger, W., Feldman, G.J., Volta, M., Andolfi, G., Gilgenkrantz, S., et al. 1997. Opitz G/BBB syndrome, a defect of midline development, is due to mutations in a new RING finger gene on Xp22. Nat. Genet. 17: 285-291.

Rao, E., Weiss, B., Fukami, M., Rump, A., Niesler, B., Mertz, A. Muroya, K., Binder, G., Kirsch, S., Winkelmann, M., et al. 1997. Pseudoautosomal deletions encompassing a novel homeobox gene cause growth failure in idiopathic short stature and Turner syndrome. Nat. Genet. 16: 54-63.

Rappold, G.A. 1993. The pseudoautosomal regions of the human sex chromosomes. Hum. Genet. 92: 315-324.

Ried, K., Rao, E., Schiebel, K., and Rappold, G.A. 1998. Gene duplications as a recurrent theme in the evolution of the human pseudoautosomal region, 1: Isolation of the gene ASMTL. Hum. Mol. Genet. 7: 1771-1778.

Rugarli, E.I., Adler, D.A., Borsani, G., Tsuchiya, K., Franco, B., Hauge, X., Disteche, C., Chapman, V., and Ballabio, A. 1995. Different chromosomal localization of the Clcn4 gene in Mus spretus and C57BL/6J mice. Nat. Genet. 10: 466-471.

Salido, E.C., Li, X.M., Yen, P.H., Martin, N., Mohandas, T.K., and Shapiro, L.J. 1996. Cloning and expression of the mouse pseudoautosomal Steroid sulphatase gene (Sts). Nat. Genet. 13: $83-86$.

Schaefer, L., Ballabio, A., and Zoghbi, H.Y. 1996. Cloning and characterization of a putative human holocytochrome c-type synthetase gene (HCCS) isolated from the critical region for microphthalmia with linear skin defects (MLS). Genomics 34: 166-172.

Slim, R., Levilliers, J., Ludecke, H.J., Claussen, U., Nguyen, V.C., Gough, N.M., Horsthemke, B., and Petit, C. 1993. A human pseudoautosomal gene encodes the ANT3 ADP/ATP translocase and escapes X-inactivation. Genomics 16: 26-33.

Snead, M.L., Lau, E.C., Zeichner-David, M., Fincham, A.G., Woo, S.L., and Slavkin, H.C. 1985. DNA sequence for cloned cDNA for murine amelogenin reveal the amino acid sequence for enamel-specific protein. Biochem. Biophys. Res. Commun. 129: $812-818$.

Soriano, P., Keitges, E.A., Schorderet, D.F., Harbers, K., Gartler, S.M. and Jaenisch, R. 1987. High rate of recombination and double crossovers in the mouse pseudoautosomal region during male meiosis. Proc. Natl. Acad. Sci. 84: 7218-7220.

Vermeesch, J.R., Petit, P., Kermouni, A., Renauld, J.C., Van Den Berghe, H., and Marynen, P. 1997. The IL-9 receptor gene, located in the $\mathrm{Xq} / \mathrm{Yq}$ pseudoautosomal region, has an autosomal origin, escapes $\mathrm{X}$ inactivation and is expressed from the Y. Hum. Mol. Genet. 6: 1-8.

Yen, P.H., Allen, E., Marsh, B., Mohandas, T., Wang, N., Taggart, R.T., and Shapiro, L.J. 1987. Cloning and expression of Steroid sulfatase cDNA and the frequent occurrence of deletions in STS deficiency: Implications for X-Y interchange. Cell 49: 443-454.

Received June 28, 2001; accepted in revised form July 15, 2001.

1832 Genome Research 


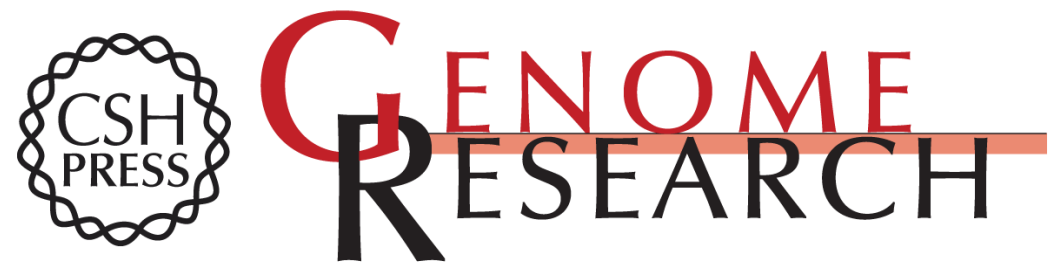

\section{A Short Pseudoautosomal Region in Laboratory Mice}

Jo Perry, Steve Palmer, Anastasia Gabriel, et al.

Genome Res. 2001 11: 1826-1832

Access the most recent version at doi:10.1101/gr.203001

References This article cites 44 articles, 9 of which can be accessed free at: http://genome.cshlp.org/content/11/11/1826.full.html\#ref-list-1

\section{License}

Email Alerting Receive free email alerts when new articles cite this article - sign up in the box at the Service top right corner of the article or click here.

\section{Affordable, Accurate Sequencing.}

To subscribe to Genome Research go to: https://genome.cshlp.org/subscriptions 